\title{
Modeling the Growth of Bacteria Streptococcus sobrinus Using Exponential Regression
}

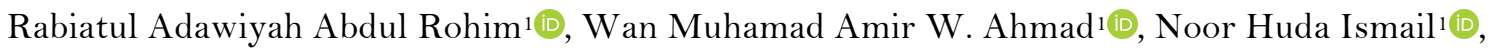

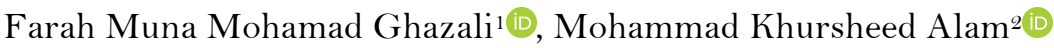

${ }^{1}$ School of Dental Sciences, Universiti Sains Malaysia, Kelantan, Malaysia.

${ }^{2}$ College of Dentistry, Jouf University, Sakaka, Kingdom of Saudi Arabia.

Author to whom correspondence should be addressed: Wan Muhamad Amir W. Ahmad, School of Dental Sciences, Universiti Sains Malaysia, Kelantan, Kubang Kerian, 16150, Malaysia. Phone: +60169869306. E-mail: wmamir@usm.my.

Academic Editor: Alessandro Leite Cavalcanti

Received: 06 November 2019 / Accepted: 15 May 2020 / Published: 15 June 2020

How to cite this article: Rohim RAA, Ahmad WMAW, Ismail NH, Ghazali FMM, Alam MK. Modeling the growth of
bacteria streptococcus sobrinus using exponential regression. Pesqui Bras Odontopediatria Clín Integr. 2020; 20:e5380.
https://doi.org/10.1590/pboci.2020.108

\begin{abstract}
Objective: To build an exponential regression model based on parameter estimation. Material and Methods: We developed a simple mathematical model to simulate the growth of bacteria and the exponential growth is often used to model population growth as such cell growth while the exponential decay is portraying a declining or decreases in the size of the population. An exponential regression method was used to fit the data and estimate growth parameter values Streptococcus sobrinus using statistical software SPSS version 20. Results: Based on the results of the parameter estimates, which is constant are 83.039 and b1 is 0.005 while R-square is 0.952 . According to the R-Square results obtained, the model is good and appropriate. Conclusion: The model can be used to find the potential biological parameters, which may be able to predict the treatment outcome. This study helps researchers to understand the specific growth rate(s), which can be used to best grow the organism.
\end{abstract}

Keywords: Models, Theoretical; Regression Analysis; Viridans Streptococci. 


\section{Introduction}

Dental caries, one of the most common infectious diseases in humans, is still a significant public health problem in several countries [1]. Mutants Streptococci (MS) (Streptococcus mutans and Streptococcus sobrinus), the most common pathogens isolated from human dental plaque are considered the major etiologic agents of caries disease.

Epidemiological studies have reported that $S$. mutans is more prevalent than $S$. sobrinus in dental plaque [2] but have also shown that the prevalence of $S$. sobrinus is more closely associated with a high caries incidence [3]. Identification of S. mutans and S. sobrinus on selective media, such as Mitis-salivarius or Mitis salivarius bacitracin agar, has used colonial morphology [4].

Several studies have reported that children harboring both S. mutans and S. sobrinus had a significantly higher caries incidence than those with either S. mutans or S. sobrinus alone [5]. Recently, a hypothesis stating that mixed colonization by S. mutans and S. sobrinus is one of the important factors for caries development has been reported [6]. For the bacterium, Streptococcus sobrinus (S. sobrinus), the comparative population size against time has been applied to predict growth by the exponential function. Modeling cell population increases have been successfully developed. Modified equations for bacterial growth can be derived for conditions to determine the lag time and growth rate of an organism [7]. The growth of an organism in a growth medium can be monitored by measuring absorbance, cell biomass (BM as cell dry weight) or cell counts per unit cell volume. Cell plate counts and an increase in metabolites of interest, as well as indirect measures, also correlate with the organism's growth rate. Most of the knowledge of microbial physiology comes from studies of isolated cell lines grown in an environment that provides adequate conditions for their propagation [8].

Therefore, when the primary objective is to detect the bacterial colonies or individual cells, a selective medium containing specific components should be used to promote better development of the target group or species. For microorganisms to grow, they require the elements that make up their chemical composition, as well as metabolic energy to synthesize macromolecules and maintain essential chemical gradients. Analysis of this process's progression should thus use carefully controlled nutrients and growth factors such as $\mathrm{pH}$, temperature, aeration, salt concentration, and ionic strength [9].

In view of the biotechnological and scientific progress of microbiology, ensuring the survival of cultures and preservative their morphological, physiological and genetic characteristics is essential for the preservation of microbial growth since dissimilar storage conditions affect cellular survival. Modeling can predict growth when microbial interaction is studied in common environments. Now, population due to such interactions can then be compared and interpreted by using a statistical modeling approach. Thus, this study aimed to build an exponential regression model based on parameter estimation.

\section{Material and Methods}

Growth of S. sobrinus $\left(1 \times 10^{5}\right)$

The biological material used in this study was collected in School of Dental Sciences, Universiti Sains Malaysia. The data is composed of two variables: the days of the culture (x) and bacterial growth (y). The data was taken from the present data available from the recently done by a researcher for nurturing selected microorganisms (Streptococcus sobrinus). Then, the data was recorded in IBM SPSS Statistics for Windows Software, version 20 (IBM Corp., Armonk, NY, USA) to evaluate microorganism growth. The selected microorganisms were kept in storage accordingly (Table 1, Figures 1 and 2). 
Table 1. Bacterial growth of culture time.

\begin{tabular}{cc}
\hline Days of the Culture $(x)$ & Streptococcus \\
\hline 1 & 82 \\
2 & 84 \\
3 & 86 \\
5 & 86 \\
9 & 87 \\
11 & $\left.87 \mathbf{1 0}^{5}\right)(\mathbf{y})$ \\
13 & 87 \\
15 & 90 \\
20 & 92 \\
23 & 94 \\
25 & 93 \\
29 & 95 \\
23 & 99 \\
\hline
\end{tabular}

Microbiological Processing

Each isolated was subcultured to a sheep blood agar plate and susceptibility testing was performed after 3 to 13 days of incubation in ambient air. The colony was placed in a test tube (A) with dilution on 1$2 \times 10^{8} \mathrm{CFU} / \mathrm{mL}(0.5 \mathrm{McF}$ arland scale) and $2 \mu \mathrm{L}$ broth. Then, $100 \mu \mathrm{L}$ colony from A was poured into $14.9 \mu \mathrm{l}$ broth with dilution on $1 \times 10^{6} \mathrm{CFU} / \mathrm{mL}$ followed by $100 \mu \mathrm{L}$ colony from $\mathrm{B}$ into $100 \mu \mathrm{L}$ broth with dilution on $5 \times 10^{5} \mathrm{CFU} / \mathrm{mL}$. Finally, a mixture of $10 \mu \mathrm{L}$ colony from $\mathrm{C}$ with $9.9 \mu \mathrm{L}$ broth using Hockey stick spread on blood agar.

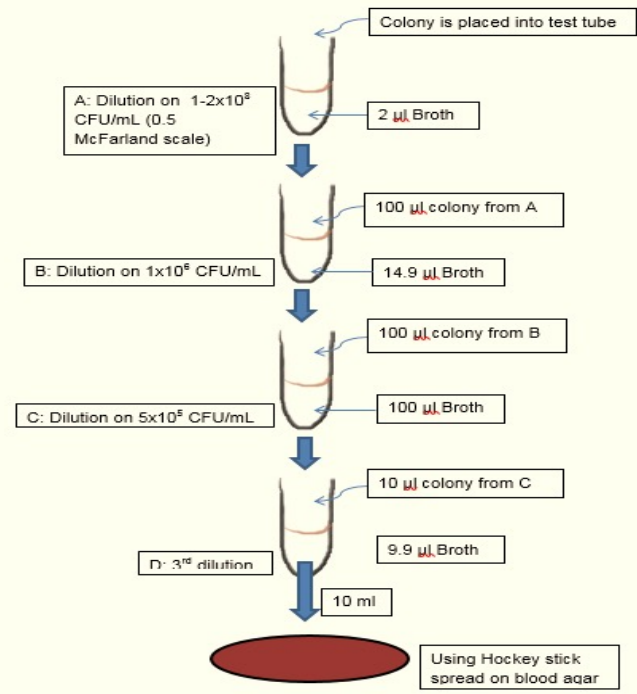

Figure 1. Steps for broth microdilution.

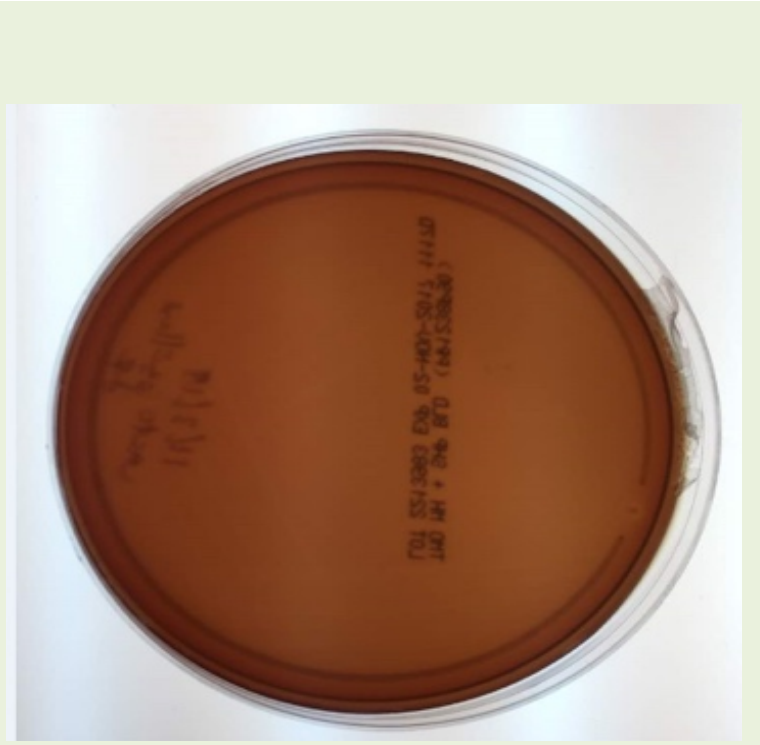

Figure 2. Blood agar of Streptococcus sobrinus.

Exponential Growth Population Model

The distribution of exponents has many applications in sciences, especially in science biology and not limited to that, the use of this dissemination extends to various other fields such as science pathology and so on. Data collected in this way can be represented by the regression exponent modeling method. It directly facilitates the researcher to observe and examine any changes that occur. For example, regression modeling methods that represent the growth or death of specific bacteria. Exponential growth modeling is a nonlinear regression technique. Exponential growth formula is as follows: $\mathrm{y}=\mathrm{Ae}^{\mathrm{bx}}$. 
It is possible to construct an exponential growth model of population, which begins with the assumption that the rate of population growth is proportional to the current population $d p / d t=k p$, where $k$ is the rate of population growth and $p$ is the population. This differential equation produces a model of the following form $p(t)=A e^{k t}$. The equation $p(t)=A e^{k t}$ represents the general solution of the differential equation [10]. When modeling a population with an exponential growth model, if the relative growth rate $k$ is unknown, it should be determined. This is usually done using the known population at two particular times. However, exponential growth models can be best to predict for the small populations in large populations with abundant resources, usually for a relatively short time period [10].

\section{Fitting Nonlinear Model}

Nonlinear parameter estimates can be obtained by using different methods. The most frequently used are (i) ordinary least squares, which minimize the sum of squared error between observations and predictions, and (ii) the maximum likelihood method, which seeks the probability distribution that makes the observed data most likely. In a case of non-normal data such as binomial or counts, the generalized nonlinear model is the best fit. Most problems encountered during the usage of standard nonlinear regression software functions are due to poor choices of competing models or an incorrect equation or starting values. The choice of estimation method can affect the parameter estimates, but in general, estimates from least squares and maximum likelihood methods tend to differ only when the data are not normally distributed and are approximately identical when the data follow a normal distribution [11].

\section{Results}

Table 2 shows the model parameter estimation for which the equations are given based on the results of the Parameter Estimates, which is constant is 83.039 and b1 is 0.005 while R-square is 0.952 .

Table 2. Model summary and parameter estimates.

\begin{tabular}{cccccccc}
\hline Equation & \multicolumn{4}{c}{ Model Summary } & \multicolumn{3}{c}{ Parameter Estimation } \\
& $\mathrm{R}^{2}$ & $\mathrm{~F}$ & $\mathrm{df1}$ & $\mathrm{df} 2$ & Sig. & constant & b1 \\
\hline Exponential & 0.952 & 218.952 & 1 & 11 & 0.000 & 83.039 & 0.005 \\
\hline
\end{tabular}

The Figure 3 refers to the exponential scattered graph of Streptococcus sobrinus to the number of days.

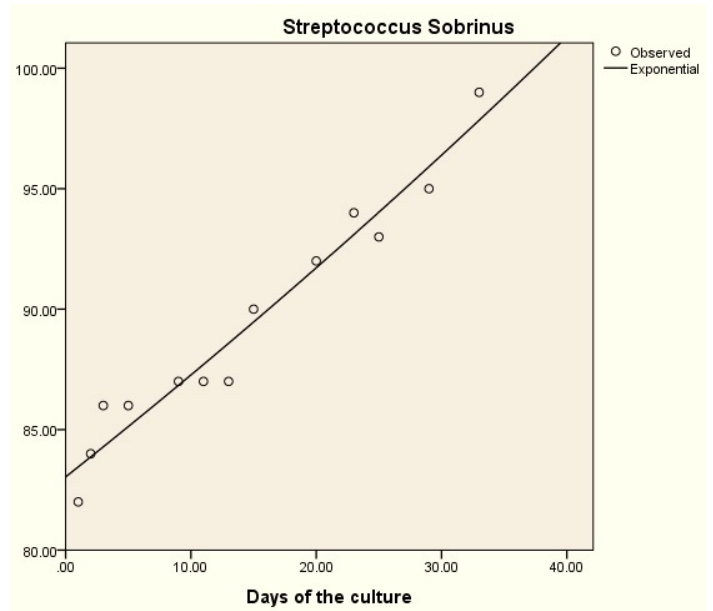

Figure 3. Scattered graph of streptococcus sobrinus vs. days of the culture. 
Based on Table 3, exponential regression model can be obtained based on the parameter estimation (exponential regression equation transforms to linear equation).

Table 3. Fitting exponential regression model.

\begin{tabular}{cccccccc}
\hline $\begin{array}{c}\text { Equation } \\
\text { Exponential }\end{array}$ & $\mathrm{R}^{2}$ & $\mathrm{~F}$ & $\mathrm{df1}$ & $\mathrm{df2}$ & Sig. & Constant & b1 \\
\hline & 0.952 & 218.952 & 1 & 11 & 0.000 & 83.039 & 0.005 \\
\hline Dependent Variable: Streptococcus sobrinus; Independent Variable: Days of the culture; Model Summary: R ${ }^{2} 0.952$ &
\end{tabular}

The exponential regression model can be obtained from the analysis written as:

$$
\begin{gathered}
\mathrm{Y}=\mathrm{A} \mathrm{e}^{b x} \\
\ln (\mathrm{Y})=\ln (\mathrm{A})+\ln \mathrm{e}^{b x} \\
\ln (\mathrm{y})=\ln (\mathrm{A})+\ln \mathrm{e}^{b x} \\
\ln (\mathrm{y})=\ln (\mathrm{A})+b x \\
\mathrm{y}=83.025 \mathrm{e}^{0.005^{x}} \\
\ln \mathrm{y}=\ln 83.025=0.005 x \\
\ln \mathrm{y}=4.41914+0.005 x
\end{gathered}
$$

\section{Discussion}

For regression models other than the linear model, R squared type goodness of fit summary statistics have been constructed for models using a variety of methods. A previous author noted that R2 or other model fit measures should be viewed as comparisons between models of the one hierarchy to assess whether the inclusion of an additional term [13].

Based on the results obtained in this study, the R-squared values approaching 1 indicate that the model is good. This is because the value close to 1 is the best fit model. For the nonlinear (exponential) functions used here, bacterial growth data can be determined by mathematical parameters that can be seen based on the curve estimation. The model fitted by nonlinear regression gave reliable estimates of the correlation coefficient $\left(\mathrm{R}^{2}\right.$ values at $\left.\mathrm{p}<0.01\right)$ for the functions used. They also assess the degree of fit of the model to each of the experimental data sets that fell close to 1 (Table 3 ) where $\mathrm{R}^{2}=1$ - (residual sum of squares) divide by the corrected sum of squares on the growth curve model.

Although the focus of this paper is $\mathrm{R}^{2}$ value and the parameter estimate of the exponential regression model, many other statistical tests and criteria are available for evaluating the quality of a model. When appropriate, these tests and criteria should be used together to determine better the quality of the exponential regression model.

The present study showed that $\mathrm{R}$ squared measure of goodness of fit for the class of exponential family regression, which includes logit, probit, Poison, geometric, gamma, and exponential [14]. However, our result differs from those of some studies in which two recent studies attempt to developed alternative measures for accident prediction models $[15,16]$. Both studies used the Poisson concept to modify existing criteria, such as $\mathrm{R}^{2}$ the scaled deviance, and the Akaike information Criterion so that the [17] bound properly can be approximately achieved. The main advantages of nonlinear models are parsimony, interpretability, and prediction [12]. Generally, nonlinear models are capable of accommodating a wide variety of mean function, although each nonlinear model can be less flexible than the linear model in terms of the variable of data they 
can describe: however, nonlinear models appropriate for a given application can be more parsimonious and more easily interpretable.

\section{Conclusion}

The model can be used to find the potential biological parameters, which may be able to predict the treatment outcome. We have demonstrated the use of an exponential regression model and a statistical package software that can be a very precise and useful tool to study the exponential growth of Streptococcus sobrinus. Besides that, this study helps to understand the specific growth rate(s), which can be used to best grow the organism.

\section{Authors' Contributions}

\begin{tabular}{|c|c|c|}
\hline RAAR & (D) $0000-0002-4882-7432$ & $\begin{array}{l}\text { Conceptualization, Methodology, Investigation, Formal Analysis, Writing - } \\
\text { Original Draft Preparation and Writing - Review and Editing. }\end{array}$ \\
\hline WMAA & (D) $0000-0003-2366-3918$ & $\begin{array}{l}\text { Conceptualization, Methodology, Investigation, Formal Analysis, Writing - } \\
\text { Original Draft Preparation and Writing-Review and Editing. }\end{array}$ \\
\hline NHI & (D) $0000-0002-5018-6048$ & $\begin{array}{l}\text { Conceptualization, Methodology, Investigation, Formal Analysis, Writing - } \\
\text { Original Draft Preparation and Writing - Review and Editing. }\end{array}$ \\
\hline FMMG & (D) $0000-0001-6772-6779$ & $\begin{array}{l}\text { Conceptualization, Methodology, Investigation, Formal Analysis, Writing - } \\
\text { Original Draft Preparation and Writing - Review and Editing. }\end{array}$ \\
\hline MКА & (D) $0000-0001-7131-1752$ & $\begin{array}{l}\text { Conceptualization, Methodology, Writing - Original Draft Preparation and } \\
\text { Writing - Review and Editing. }\end{array}$ \\
\hline
\end{tabular}

\section{Financial Support}

Universiti Sains Malaysia (Grant No.1001/PPSG/8123051).

\section{Conflict of Interest}

The authors declare no conflicts of interest.

\section{References}

[1] Ramos-Gomez FJ, Weintraub JA, Gansky AS, Hoover CI, Featherstone JDB. Bacterial, behavioral and environmental factors associated with early childhood caries. J Clin Pediatr Dent 2002; 26(2):165-73. https://doi.org/10.17796/jcpd.26.2.t6601j3618675326

[2] Loesche WJ. Role of streptococcus mutans in human dental decay. Microbial Rev 1986; 50(4):353-80.

[3] Hirose H, Hirose K, Isogai E, Miura H, Ueda I. Close association between streptococcus sobrinus in the saliva of young children and smooth-surface caries increment. Caries Res 1993; 27(4):292-7. https://doi.org/10.1159/000261553

[4] Svanberg M, Krasse B. Comparative recovery of mutans streptococci on two selective media. Caries Res 1990; 24(1):36-8. https://doi.org/10.1159/000261235

[5] Okada M, Soda Y, Hayashi F, Doi T, Suzuki J, Miura K, et al. Longitudinal study of dental caries incidence associated with Streptococcus mutans and streptococcus sobrinus in pre-school children. J Med Microbiol 2005; 54(Pt 7):661-5. https://doi.org/10.1099/jmm.0.46069-0

[6] Seki M, Yamashita Y, Shibata Y, Torigoe H, Tsuda H, Maeno M. Effect of mixed mutans streptococci colonization on caries development. Oral Microbiol Immunol 2006; 21(1):47-52. https://doi.org/10.1111/j.1399-302X.2005.00253.x

[7] Bernaerts K, Dens E, Vereecken K, Geeraerd AH, Standaert AR, Devlieghere F, et al. Concept and tools for predictive modeling of microbiol dynamics. J Food Prot 2004; 67(9):2041-52. https://doi.org/10.4315/0362-028x-67.9.2041

[8] Dalgaard P, Koutsoumanis K. Comparison of maximum specific growth rates and lag time estimated from absorbance and viable count data by different mathematical models. J Microbiol Methods 2001; 43(3)183-96. https://doi.org/10.1016/s0167-7012(00)002 19-0 
[9] Brooks GF, Butel JS, Ornston LN. Jawetz, Melnick \& Adelberg's Medical Microbiology. 25th ed. New York: McGraw Hill; 2010.

[10] Hathout D. Modeling population growth: exponential and hyperbolic modeling. Applied Math 2013; 4:299-304. https://doi.org/10.4236/am.2013.42045

[11] Myung IJ. Tutorial on maximum likelihood estimation. J Math Psychol 2013; 47:90-100. https://doi.org/10.4236/am.2013.42045

[12] Bates DM, Watts DG. Nonlinear Regression Analysis and its Application. New York: Wiley; 2007.

[13] Anderson-Sprecher R. Model comparison and R R Am Stat 1994; 48:113-17. https://doi.org/10.1080/00031305.1994.10476036

[14] Cameron AC, Windmeijer FAG. An R squared measure of goodness of fit for some common nonlinear regression models. J Econom 1997; 77(2):329-42. https://doi.org/10.1016/So304-4076(96)01818-0

[15] Miaou SP. Measuring the Goodness of Fit of Accident Prediction Models Oak Ridge National Laboratory. Center for Transportation Analysis. Springfield: National Technical Information Service; 1996.

[16] Fridstrøm L, Ifver J, Ingebrigtsen S, Kumala R, Thomsen LK. Measuring the contribution of randomness, exposure, weather and daylight to the variation in road accident counts. Accid Anal Prev 1995; 27(1):1-20. https://doi.org/10.1016/0001-4575(94)e0023-e

[17] Roy Jorgensen Associates, Inc. NCHRP Report 197: Cost and Safety Effectives of Highway Design Elements. TRB, National Research Council Washington, D.C, 1978. 